\section{We have lift-off! The Launch of Competence by Design in Canada}

The transition to the Royal College of Physicians and Surgeons of Canada brand of Competency-Based Medical Education (CBME), entitled "Competence By Design (CBD)," will begin on July $1^{\text {st }}$ 2019 for many internal medicine programs including core internal medicine and general internal medicine fellowship programs. For many involved with postgraduate medical education, it is a journey into the unknown. To help ease this transition, herein is a brief summary of CBME for those less familiar with the upcoming changes.

\section{What Inspired This Transition?}

The push to reform educational design from a process-based system to one framed around training outcomes or competencies has been ongoing since the early 2000s. ${ }^{1}$ The CanMEDS initiative, first adopted in 1996 and updated in 2005, defines a robust competency framework that is recognized internationally. However, implementation and assessment of the CanMEDS competency framework has remained a challenge within the traditional Canadian training structures. Thus, the Royal College created a CBME structure entitled CBD, which led to an overhaul of the curricular and assessment system design for all postgraduate training programs, with the goal focusing on training outcomes, emphasizing the acquisition of competencies and promoting learner-centredness. ${ }^{2}$

\section{What Are the Major Differences to Expect?}

There are many changes needed in order to align postgraduate programs with the new $\mathrm{CBD}$ requirements. These include:

- Reframing developmental milestones from traditional time-based (postgraduate year 1, 2, 3) to those outlined by the College (Transition to Discipline, Foundations, Core of Discipline and Transition to Practice).

- Creation of a program of assessment, emphasizing workplacebased assessment (WBA) tools, in order to ensure direct observation and documentation of achieved competence. The WBA program has been designed using Entrustable Professional Activities (EPAs) to capture the core skills (outcomes or competencies) required by a physician in a given specialty. ${ }^{3}$ The Royal College, universities, and individual programs are working to create an electronic platform to capture these multiple assessments over time for each trainee. There are currently many different platforms in operation across the country.

- Creation of a process to promote "assessment for learning," and to encourage trainee reflection on their assessment data, progression, and competence development. Strategies for this have included creating the role of an academic coach.
- Creation of a process to review the assessment data, and ensure the fair promotion of the trainee throughout the training program. This has led to the widespread operationalization of "competence committees."

Undoubtedly, challenges lie ahead given the extent of change that will affect residents, faculty, administration, information technology systems, hospitals, and universities. Strong leadership and change management is critical during this transition period. On balance, CBME appears to be a positive next step of continuous quality improvement of our medical education system. We encourage ongoing research that documents and understands the impact of this immense transition. Let the journey begin!

\section{References}

1. Carraccio C, Wolfsthal SD, Englander R, et al. Shifting paradigms: from Flexner to competencies. Acad Med 2002;77. doi:10.1097/00001888-200205000-00003.

2. Frank JR, Snell LS, Cate OT, et al. Competency-based medical education: theory to practice. Med Teach 2010;32(8):638-45. doi:10.3109/01421 59x.2010.501190.

3. Ten Cate $\mathrm{O}$ and Scheele F. Competency-based postgraduate training: can we bridge the gap between theory and clinical practice? Acad Med 2007;82(6):542-47. doi:10.1097/ACM.0b013e31805559c7.

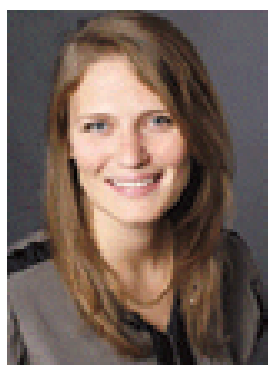

Leslie Martin, MD, MHPE, FRCPC, is an Assistant Professor, Division of General Internal Medicine, Department of Medicine at McMaster University, Hamilton, ON.

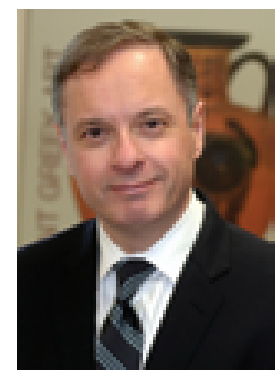

James Douketis MD, FRCPC Editor-in-Chief, Canadian Journal of General Internal Medicine 